\title{
El proceso de urbanización en la meseta septentrional
}

\author{
Pilar Gonzalez Serrano
}

\section{RESUMEN SUMMARY}

En el proceso de romanización de la Peninsula lbérica jugaron un papel decisivo las urbes o ciudades surgidas como transofrmación de las indigenas en las zonas más civilizadas, $o$ a forciori, en áreas del interior. En el marco de sus esructuras los pueblos indigenas aprendieron a vivir, a pensar y a hablar "a la romana" $y$. finalmente,

a ser ciudadanos de pleno derecho.

La mayoría de las ciudades de la meseta conservaron su nombre indigena, lo que da muestra de su importancia y, por lo tanto, de su continuidad como núcleo de aglomeración urbana, digno de consideración, a pesar de la resistencia que hubieran podido presentar frente a la dominación romana. Tal es el caso de Segróbriga, Ercávica, Toletum, Consabura, Laminium, Mentesa, Oretum, Complutum, Segisama, Uxama, Numantia, etcétera.
During the romanization process of the Iberic Peninsula, the urbes or cities played and important role. as well as the ones which were a transformation of the indigenous ones in the more civilizate regions, and the ohers which were borned a forciori, in interior areas. In this way the native people learned to live, to think and to speak "a la romana", and finally, to become the full right citizens.

The greatest part of the Meseta's cities keeped their own indigenous name, what shows their importance and also their continuity as urban centers, very considerates in spite of their resistence against the roman domination. In this sense we can make stand out: Segóbriga, Ercávica, Toletum, Consabura, Laminium, Mentesa, Oretum, Complutum, Segisama, Uxama. Numantia, etcétera. 
El proceso de romanización de la Península Ibérica, por la complejidad de los múltiples aspectos militares, políticos, económicos y sociales que en él confluyeron, es susceptible de ser enfocado y criticado desde puntos de vista muy diversos, pero, en cualquier caso, es evidente que, en dicho proceso, jugaron un papel decisivo las urbes o ciudades surgidas como transformación de las indígenas en las zonas más civilizadas, o a forciori, en tierras del interior. En el nuevo marco de sus estructuras los pueblos indígenas aprendieron a vivir, a pensar y a hablar "a la romana" $y$, a la postre, a ser ciudadanos de pleno derecho. Bien comunicadas entre sí, primero por calzadas militares, convertidas, más tarde, en vías comerciales, las ciudades fueron los agentes más dinámicos de la transformación programada, hasta el punto de que los territorios que quedaron fuera del ámbito de la colonización y municipalización propuesta por César, se mantuvieron en estadios retardatarios hasta muy avanzados los tiempos imperiales.

La mayoría de las ciudades de la Meseta conservaron su nombre indígena en época romana, lo que da buena muestra de su importancia y, por lo tanto, de su continuidad como núcleo de aglomeración urbana, digno de consideración a pesar de la resistencia que hubieran podido presentar. Tal es el caso de Segóbriga, Ercávica, Toletum, Consabura, Laminium, Mentesa, Oretum, Complutum, Segisama, Uxama, Termantia, Numantia, etcétera.

Dentro de cada provincia funcionaron como centros administrativos las civitates, de características muy modestas, en un principio, pero rodeadas de un territorio rústico de cuya explotación vivían no sólo sus moradores, sino también la población en él asentada en pequeñas y dispersas concentraciones. Su condición jurídica se correspondía con la forma en que se habia realizado su sumisión. Así, se dividieron en foederatae o aliadas, cuando su integración en el Estado romano se había realizado pacíficamente, por medio de un pacto; liberae, si se habian entregado sin condiciones, por lo que se las consideraba exentas del pago de tributos e independientes en la gestión de sus asuntos internos; stipendiariae, si habían sido conquistadas por las armas, lo que las obligaba al pago de un tributo anual o stipendium, a proporcionar soldados auxiliares y a la renuncia de su derecho propio.

En las zonas menos romanizadas, las entidades sociales de carácter tribal, los populi, fueron integrándose, poco a poco, en civitates de nueva planta, a medida que iba ganando terreno el proceso de pacificación e integración. Por esta razón y teniendo en cuenta la complejidad étnica del área meseteña septentrional, para entender las claves de su proceso de 
romanización, hay que tener muy en cuenta la condición y variedad de sus habitantes y sus diferentes sistemas de vida y economia.

\section{LOS PUEBLOS DE LA MESETA SEPTENTRIONAL}

De entre los pueblos celtas (los keltoi de los griegos y los celti de los romanos) que ocuparon parte de la Meseta entre los siglos vill y vII a.C., los más antiguos fueron los beribraces, asentados en la zona más oriental de la Meseta y parte de Valencia. Mencionados por Avieno, sabemos por este mismo autor que eran "gente salvaje y feroz". La siguiente oleada estuvo protagonizada por pelendones, berones y turmódigos (o turmogos). Los pelendones se instalaron en la actual provincia de Soria y, enfrentados con los arévacos, se vieron forzados por éstos a confinarse en los territorios más montañosos que ambos pueblos compartían. Entre las ciudades que atribuyen a los pelendones sobresalen la de Numancia (luego arévaca), Augustóbriga y Savia (Soria). Tras la derrota de Numancia, los romanos, en su afán de aniquilar a los vencidos, devolvieron parte de los territorios arévacos a sus antiguos ocupantes.

En cuanto a los turmódigos, se extendieron por la zona noreste de la Meseta Norte, por tierras burgalesas y palentinas, coincidiendo su expansión con el área donde se han localizado las necrópolis de Miraveche y Monte Bernorio. Los berones se distribuyeron por el valle del Ebro, ocupando, tan sólo, una mínima parte la cuenca del Duero.

Por otro lado, se encuentran los celtíberos, cuyas raíces étnicas aún siguen siendo debatidas. Con este nombre se designó a la mayor parte de los habitantes de ambas Castillas en el período prerromano y son varias las fuentes en que se les menciona. Entre ellas destacan los escritos de Diodoro, Plinio, Apiano, Marcial, Ptolomeo y, de modo especial, Estrabón y Tito Livio. El primero de todos ellos fue quien, tomando los datos de Poseidonio, emitió la teoría, tenida durante mucho tiempo como tradicional, de que los celtíberos eran el resultado de la fusión de iberos y de celtas, quienes tras de guerrear entre sí, sellaron la paz y decidieron compartir territorios uniéndose, incluso, por vínculos de sangre. Sin embargo, en la actualidad prevalece la opinión de autores, como Antonio Tovar, que los consideran pueblos de estirpe indoeuropea con una manifiesta influencia cultural ibérica. De ahi que haya grupos que unas veces aparezcan citados como celtas y otros como celtíberos, lo que sucede, por ejemplo, con los pelendones, al parecer restos de una invasión céltica anterior al siglo vı a.C. y que permanecieron independientes hasta la lle- 
gada de una nueva oleada en la que hicieron su aparición los arévacos. A grandes rasgos, puede decirse que la Celtiberia estuvo situada entre las líneas que marcan los valles de los ríos Jalón y Jiloca, la margen derecha del Ebro, cuenca superior del Duero y la alta llanura occidental de la meseta septentrional.

De entre los grupos que poblaron la región castellano-leonesa, los más importantes fueron los arévacos, vacceos y vettones. Los arévacos, cuyo nombre, según Plinio, les venia dado por el río Areva (actual Araviana, que baja desde ef Moncayo y desemboca en el Retuerto, afluente del Duero por su margen izquierda) se asentaron en las zonas del alto Duero, correspondientes a la actual provincia de Soria, avanzando por las comarcas de Atienza y Sigüenza. Según Estrabón, eran una de las cuatro unidades que junto con lusones, pelendones y celtíberos (propiamente dichos) componian el gran tronco celtibérico. Por su parte, Polibio incluyó a belos y titos en su relación, mientras que Ptolomeo excluyó a arévacos y pelendones de la suya. Livio y Plinio citaban a los pelendones entre los celtiberos y Apiano a los vacceos. Al parecer los arévacos y vacceos tuvieron un lenguaje común y, de hecho, en muchas campañas bélicas lucharon unidos y prestándose ayuda mutua. Desde el punto de vista filológico, se considera a los arévacos como vacceos orientales. Debieron de desarrollar una cultura eminentemente pastoril que se ha asociado con la de los castros sorianos, cuyo florecimiento se produjo en los inicios de la Segunda Edad del Hierro. Por el norte limitaban con pelendones, berones y várdulos; por el este con vascones y celtiberos; por el sur con los carpetanos y por el oeste con los vacceos.

Sus principales ciudades fueron: Numantia (Numancia, en Cerro Garray, Soria), Termantia (Termancia, Montejo de Liceras, Soria), Segontia (Sigüenza), Clunia, Celtiberiae finis (Peñalba de Castro, Burgos), Veluca (Calatañazor), Segouia (Segovia), Uxama (Osma, Soria), Segeda (Belmonte de Calatayud), Contrebia Leukade (¿Inestrilla?) y otras, ya que las enumeraciones varian según los autores.

Los vacceos se establecieron en el noroeste de la Meseta central, ocupando la actual «tierra de campos» ubicada principalmente entre el Duero y el Pisuerga. Se extendieron desde la zona montañosa de Palencia hasta Salamanca, y desde Roa a Segisamo (Sasamón) hasta el Esla que servía de frontera con los astures. Dedicados principalmente a la agricultura, base de su subsistencia, practicaron un sistema de colectivismo agrario para el cultivo y explotación de las tierras que llamó la atención de los autores clásicos. Como ciudades vacceas se mencionaban a Arbucala (Toro, en Zamora), Intercatia (Villalpando o cerca del Valderaduey, Zamora), Lacóbriga (Carrión de los Condes, Palencia), Pallantia (Palencia), Cauca (Coca, Segovia), etc. 
Los vettones, por su parte, ocuparon la zona más occidental de la Meseta central, limitada por carpetanos y lusitanos. Aunque no pertenecian al tronco celtibérico recibieron y asimilaron las influencias de las estirpes de origen indoeuropeo que les rodeaban. Sus raíces étnicas aún siguen siendo problemáticas, pero prevalece la hipótesis de su carácter indígena precéltico, ya que tanto en esta zona, como en la habitada por carpetanos y lusitanos, cada vez se pone más de relieve la existencia de un sustrato étnico meridional que se percibe por manifiestas diferencias con la cultura de los grupos celtibéricos. A mediados del siglo / d.C. Se extendían, poco más o menos, por las provincias de Cáceres, sur de Salamanca, Ávila y zona occidental de Toledo. Sus territorios coincidian, por lo tanto, con los limites del área cultural de las Cogotas II y la de los verracos, las esculturas zoomorfas más significativas del llamado arte celta. Se cree que, en un principio, fueron pueblos agricultores, pero, tras sufrir la invasión arévacavaccea en el siglo III a.C., se vieron obligados a cambiar su género de vida convirtiéndose en ganaderos.

Ciudades importantes de los vettones fueron Salmantica (Salamanca), aunque Polibio la cita como vaccea en el momento en que fue atacada por Anibal, Cottaeobriga (Almeida, Zamora), Miróbriga (Ciudad Rodrigo, Salamanca), Capara (cerca de Plasencia, Cáceres) y Sentica (Prades de la Sierra, Salamanca). La identificación de Obila u Oliva (citada por Ptolomeo) con Ávila sigue siendo dudosa.

Por último, hay que citar a los autrigones, centrados en la comarca burgalesa de la Bureba y a los astures, quienes no sólo ocuparon la región de Asturias, sino también parte de la actual provincia de León, donde la mineria del oro alcanzó un gran desarrollo. Tanto las tierras de los astures como las de la parte oriental de Galicia se convirtieron, a partir de la época de Augusto, en una de las zonas mineras de mayor interés para la economia romana hasta muy avanzado el siglo III d.C.

\section{LAS CIUDADES ROMANAS DEL ÁREA SEPTENTRIONAL MESETEÑA}

La mayoría de las ciudades meseteñas romanas, como ya se ha señalado, conservaron su nombre indigena, lo que indica que siempre que fue posible se prefirió proceder a su reestructuración antes que a una nueva fundación. De hecho, el establecimiento de ciudades de nueva planta fue un recurso impuesto por las circunstancias defensivas o administrativas de cada región, sobre todo después de la puesta en marcha de los planes de organización territorial iniciados por César y llevados a cabo por Augusto. 
En la Meseta Norte pertenecen al grupo de las ciudades remodeladas sobre antiguos núcleo indigenas las de Numantia (Numancia), Termancia (Tiermes), Clunia (al parecer trasladada a un alto situado frente a la ciudad prerromana), Uxama (Osma) etc.; y al segundo Asturica Augusta (Astorga), sobre el terreno ocupado por un campamento romano, León (asimismo sobre otro campamento, en este caso el de la Legio VII Gemina), Segouia (Segovia), etc.

Por razones de espacio, es imposible, en este caso, estudiar cada una de ellas en la medida de su importancia. Por esta razón nuestro propósito no puede ser otro que el de englobarlas en una visión de conjunto, resaltando sus aspectos más destacados para poder entender el papel que jugaron en el proceso de la conquista y ocupación de sus tierras.

Asturica Augusta (figura 1) fue la capital y el centro jurídico de los astures, en el territorio de los amacos, según señaló Ptolomeo. En ella confluían las vías que procedían de Brácara, Zaragoza, Tarragona y Burdeos. Plinio la califica de magnífica, sin duda por su importancia como centro del rico territorio minero del noroeste. En ella había un destacamento de soldados con un procurator metallorum encargado de la vigilancia de las minas para evitar los robos no sólo de los bandidos que solian merodear por la zona, sino también de los propios trabajadores que eran nativos.

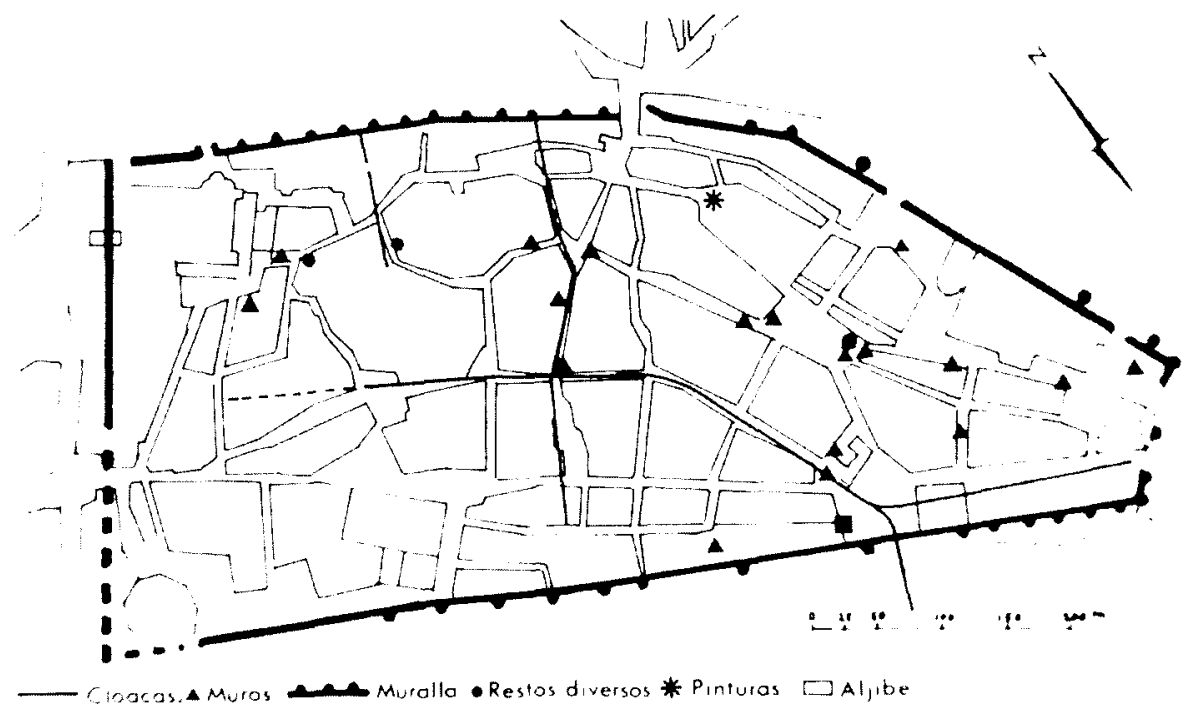

Figura 1. Plano de la antigua ciudad de Asturica Augusta (actual Astorga). 


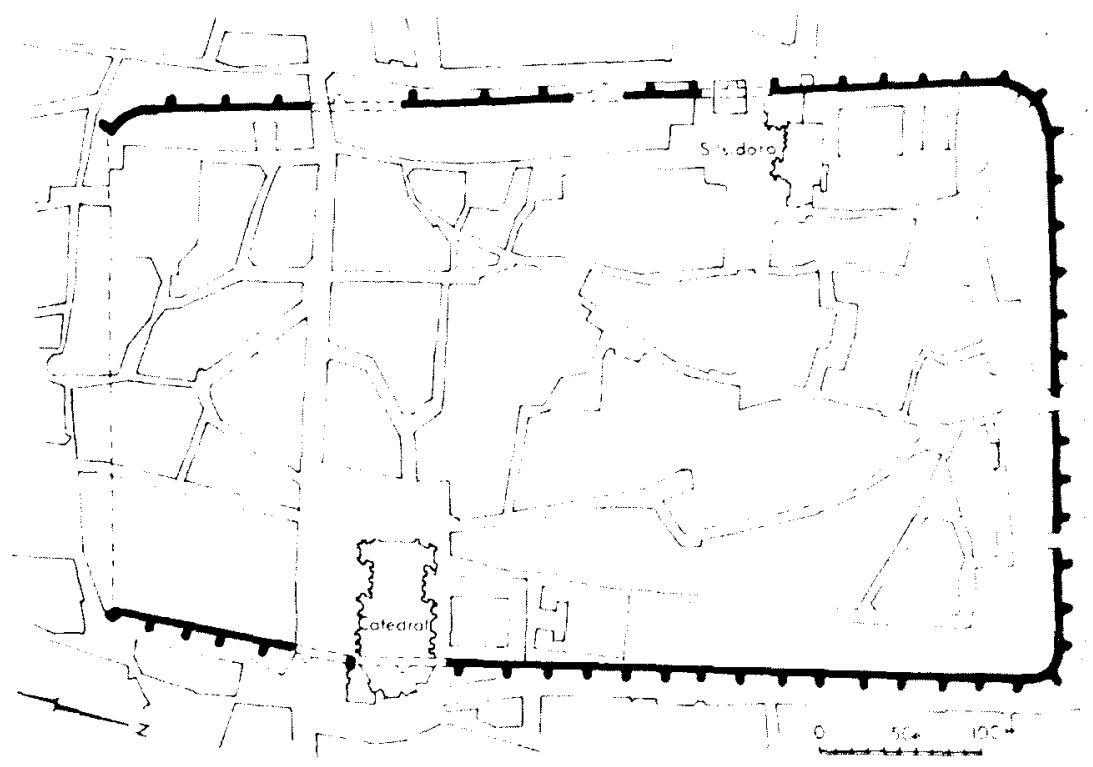

Figura 2. Plano de la antigua ciudad de León.

En época visigoda fue saqueada por Teodorico, en el año 457, y más tarde por los suevos. En el siglo XIX las murallas sufrieron daños importantes durante la invasión francesa, sin embargo, se conservan completas. Su fecha se ha situado en el siglo III d.C. Los estudios y exploraciones realizadas en los años cincuenta por José María Luengo, dieron a conocer la red de cloacas, con lo que se pudo reconstruir la planimetria de la ciudad, obtener un gran número de datos y recuperar objetos de interés: inscripciones, cerámicas, monedas, un sarcófago, un cipo, etc.

León (figura 2) fue la sede de la Legio VII Gemina (Castra legionis Septimae Geminae) reclutada por Galba en Hispania, en el año 68 d.C., como sabemos por Tácito, Dión Casio y Suetonio. Acompañó a este militar a Roma y desde allí fue enviada a Panonia para disolver la $X$ Gemina. Parece ser que tomó parte en la batalla de Bedriaco, y que luego fue devuelta a la frontera de Panonia por Otón. Más tarde, se pronunció en favor de Vespasiano, y su jefe Antonio Primo estuvo al frente de las operaciones llevadas a cabo contra los ejércitos de Vitelio. Tras duros enfrentamientos y numerosas bajas, la Legión VII regresó a Roma. Desde alli debió de retornar a Panonia y estuvo en el Rhin hasta el año 78 d.C. Aunque algunos autores, entre ellos Mommsen, han supuesto que su sede en Hispania debió de ser primero Asturica Augusta, no hay datos reales que lo confir- 
men. Una larga serie de inscripciones y vestigios arqueológicos demuestran que la citada Legión estuvo, en lo que hoy es la ciudad de León, desde época de Trajano hasta fines del siglo III.

La ciudad parece haberse desarrollado a partir de las cannabae (barracas), población flotante que vivía al socaire de la Legión. Su perímetro, de forma rectangular, mide $570 \times 350 \mathrm{~m}$., y fue reforzado en el Bajo Imperio por una muralla de $5,25 \mathrm{~m}$., de espesor, provista de cubos y adosada a un muro interior, de $1,80 \mathrm{~m}$. de grueso. La similitud del aparejo con los de la basílica paleocristiana de Marialba, sita a $405 \mathrm{~km}$. de la ciudad de León, hizo pensar a Garcia y Bellido que tal vez fuese del siglo IV. Sin embargo, parece ser que la fecha de la muralla exterior debe situarse en el siglo III, que es cuando se fortificaron otras muchas ciudades hispanas, mientras que la interior debió de construirse a mediados del siglo I d.C. En León terminaba una vía que venía de Milán y, sin embargo, las vías de Astorga a Zaragoza y a Tarragona no pasaban por ella; sí existía, en cambio, una calzada que la unía con Salamanca.

Recientes hallazgos, entre ellos los restos del graderio de un teatro, al parecer de época anterior a la de la instalación de la Legio VII han puesto en entredicho el origen castrense de León. Es de esperar que en futuras campañas de excavación tales noticias se conviertan en datos más amplios y concretos.

Por otro lado, en la provincia de León hay que situar una de las principales explotaciones auríferas, situadas en la región del Bierzo. Explotaciones dependientes, de forma directa, de los emperadores romanos que aquí encontraron un magnífico filón, sobre todo, para sus acuñaciones monetales.

Debemos, sobre todo a Plinio el Viejo (XXXIII, 70-78) la descripción del trabajo de las minas de oro y la explicación detallada del procedimiento que denomina de la arrugia o ruina montium y que, en su opinión, era superior a la obra de los gigantes. Esta técnica consistía en el minado de los montes, hasta conseguir desplomarlos, y el lavado de las tierras desmoronadas con enormes masas de agua traídas por canales y acueductos desde donde fuera necesario, "hasta más de mil millas", como dice el propio Plinio. Sus consecuencias se pueden apreciar hoy en las llamadas Médulas (figura 3), región recorrida por el Sil. Alli pueden verse los restos de una enorme explotación aurifera (los ourales) de la que los romanos, durante unos trescientos años (desde comienzos del siglo I a finales del III d.C.) y contando con el trabajo de miles de esclavos, extrajeron casi un milión de kilos de oro, dejando, como vestigio, un paraje singular (declarado Monumento Histórico-Artístico en 1931). Desde el mirador de Ore- 


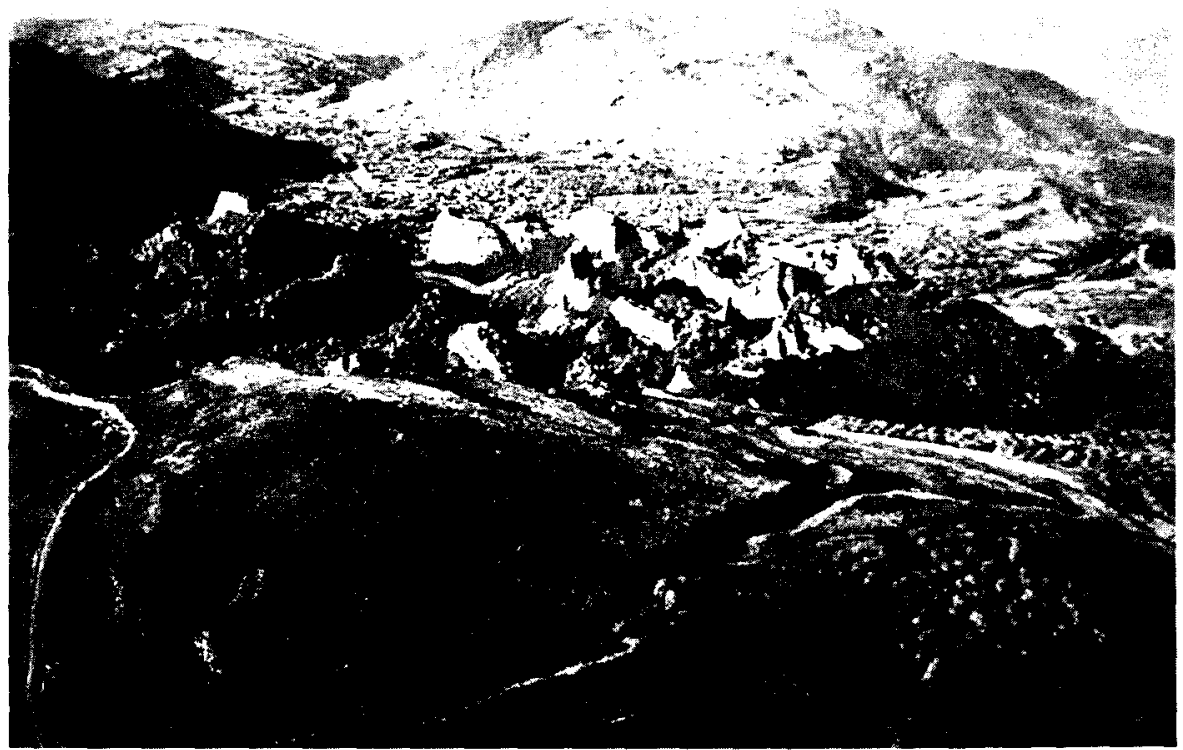

Figura 3. Paisaje de las Médulas (los "ourales" del Sil) en el Bierzo (León).

Ilán el espectáculo resulta impresionante, ya que lo que se divisa es un conjunto sobrecogedor de cuevas y conos de barro rojo cubiertos, a tramos, por una fronda verde que les confiere una especial belleza, ya cantada por Bernardo de Balbuena:

\footnotetext{
Aquellas son del Vierço las montañas, $y$ aquestas puntas altas y vermejas sus Médulas serán, cuyas entrañas solían vomitar oro entre las rexas.
}

El nombre de médulas se suele aplicar a todo lugar donde ha existido una explotación aurifera del tipo arrugia y cuya etimologia sigue siendo discutida. Según el Padre Flórez deriva del latín metalla, es decir mina. Ambrosio de Morales, en su libro Viaje por León. Galicia y Asturias (1572) sugirió que dicho nombre debe relacionarse con cinco o seis picachos de tierra roja que, por su forma alta y redondeada, recordaban a los montones de paja, de silueta similar, que en la zona se denominan medas. Y otra posibilidad es la que hace derivar médul de modulus término técnico aplicado a los tubos de acueducto usados en el sistema hidráulico empleado en este tipo de explotaciones.

Quizás fue aqui donde estuvo antes el Mons Medulius, último foco de la heroica resistencia de los galaicos contra las legiones de Augusto. Las 
noticias que sobre el particular nos ofrece Plinio se resumen, al final, con el siguiente comentario: "Según algunos, Asturias, Gallaecia y Lusitania suministran por este procedimiento 20.000 libras de oro, la mayor parte de él procedentes de Asturias (terrirorio de los astures agustani); en ningún otra parte se ve tal abundancia mantenerse durante tantos siglos".

Del relato de los historiadores Floro y Orosio se desprende que la importancia económica de estos yacimientos auríferos fue lo que motivó la presencia en Hispania del propio Augusto, quien dirigió personalmente la campaña de dominación de la zona entre los años 26 y 25 a.C., acompañado de sus mejores generales y al frente de unas diez legiones, es decir, sesenta mil hombres. En el año 26 a.C., tras largo asedio, fue tomado el castro de Bergida, centro neurálgico del Bierzo y que, más tarde, se denominaría Bergidum Flavium (Castro de la Ventosa), ya romanizado y convertido en el centro administrativo de las explotaciones auriferas. Un año después, también fue dominada otra de las grandes ciudades de los astures, Lancia, sita entre los ríos Esla y Porma, en el lugar hoy conocido por Castro de Villasabariego, a unos $15 \mathrm{~km}$. de León. Tras una dura resistencia, sus habitantes antes de rendirse al general Carisio prefirieron prender fuego a la ciudad y morir entre sus muros.

Lo que sorprende es el gran silencio mantenido acerca del emplazamiento concreto de las minas, a pesar de las noticias que de ellas nos transmiten distintos autores clásicos (Estrabón, Plinio, Diodoro, Pomponio Mela, Justino, Lucano, etc.), ninguno de los cuales da muestras de haberlas visitado. Esta peculiar circunstancia ha llevado a pensar que fue el propio Augusto y, más tarde, sus sucesores quienes procuraron escatimar noticias acerca de unas explotaciones auríferas de tal importancia y cuya explotación corría a cargo, del Estado, es decir, directamente del emperador.

Segouia (Segovia), situada en la ladera norte de la sierra de Guadarrama, en el peñón oblongo excavado desde hace milenios por los arroyos serranos del Eresma y del Clamores, es famosa, en la actualidad, por su alcázar y su acueducto, una de las obras de ingenieria más famosas de la Hispania romana. Sus habitantes históricos fueron los arévacos, según dicen Plinio y Ptolomeo, aunque Schulten opina que era una ciudad vaccea. En las fuentes clásicas aparece citada por primera vez con motivo de la guerra contra Viriato y, más tarde, en la de Sertorio. A partir del siglo I de la Era, la ciudad fue creciendo en torno al acueducto que, construido en época de Nerva, según demostró Blanco Freijeiro, traía el agua desde la Fuenfría, manantial sito a unos $15 \mathrm{~km}$. del núcleo urbano (figura 4). 


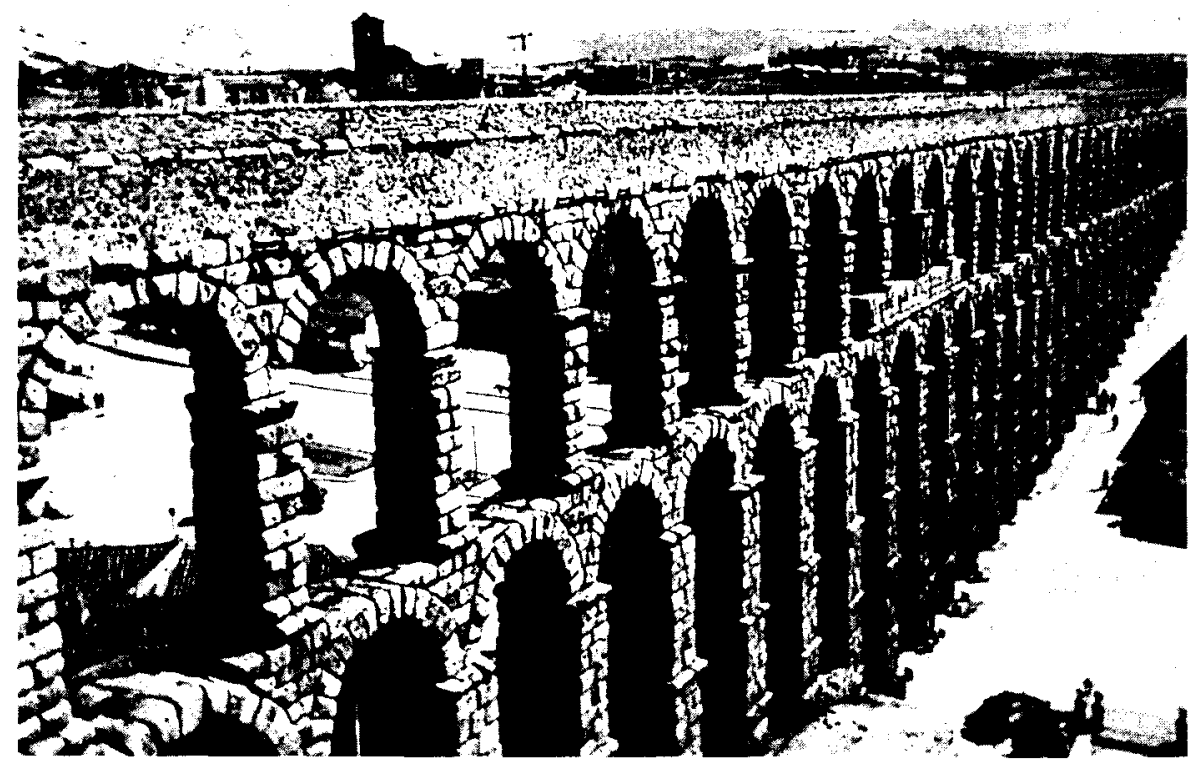

Figura 4. El acueducto de Segovia, construido en época del emperador Nerva, en el siglo 1 de la Era.

Ciudades importantes de esta provincia fueron también Cauca (Coca), de donde procedia Teodosio, y Septempublia (Sepúlveda). Los romanos conquistaron pronto esta zona dado su interés estratégico como acceso al valle del Duero. A partir del siglo i perteneció al convento jurídico de Clunia, en la Tarraconense.

Clunia (figura 5), centro importante de los arévacos, estuvo situada en el extremo sureste de Burgos, entre los municipios de Peñalba de Castro y Coruña del Conde, en la vía que iba de Caesaraugusta (Zaragoza) a Asturica Augusta (Astorga). Como ciudad romana fue cabeza del convento jurídico cluniense en los límites de la Celtiberia estuvo situada en el actual término municipal de Coruña del Conde (Burgos) y se alzó sobre una colina situada frente al emplazamiento de la ciudad prerromana. Las distintas excavaciones en ella realizadas (1915-16, Ignacio Calvo; 1932, Blas Taracena; desde 1958, Pedro Palol), han sacado a la luz los edificios más significativos de toda ciudad romana: el foro, la basílica, templos adyacentes, el teatro, etc.

El foro, una plaza rectangular ( $140 \mathrm{~m} \times 100 \mathrm{~m}$.), estuvo rodeado, en sus lados largos, por tiendas (tabernae). Uno de estos locales se dedicó al culto de la familia imperial julio-claudia, por lo que en ella se exhibió una galería de retratos pertenecientes a los miembros más destacados de esta 


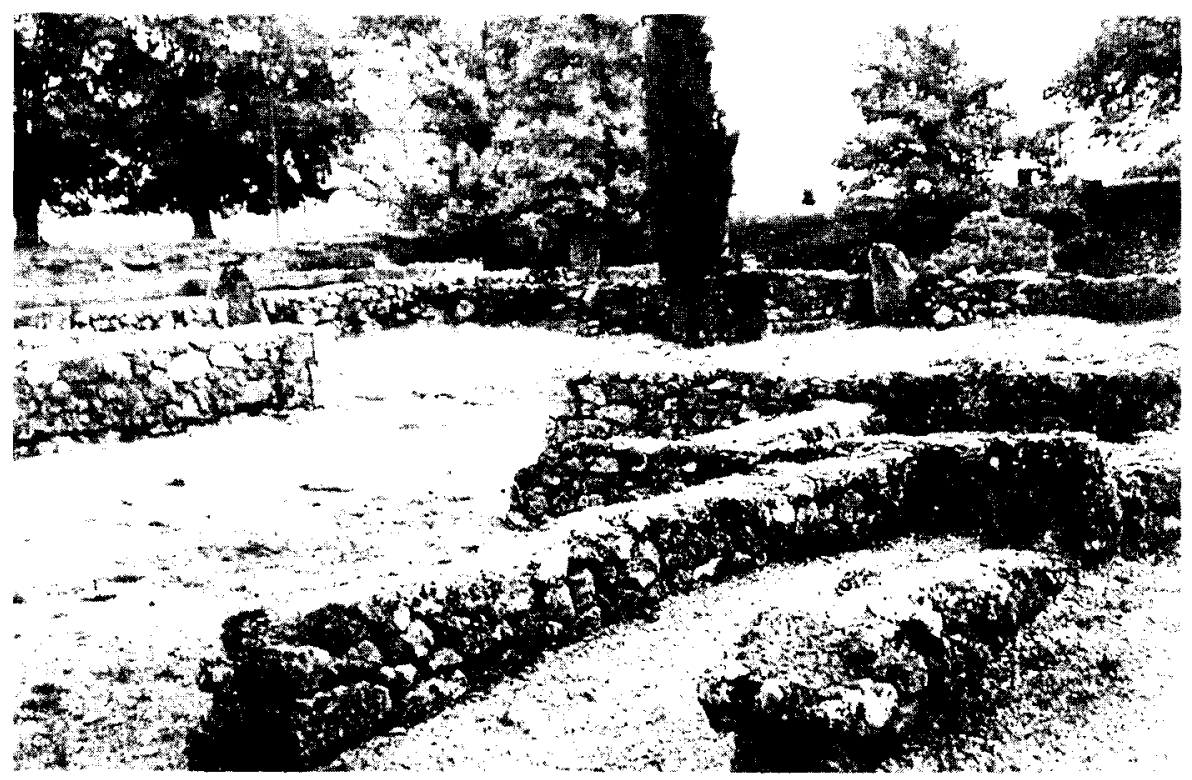

Figura 5. Restos de la ciudad romana de Clunia.

dinastía imperial. En los lados cortos se alzaron una basílica, en el del noroeste, que ocupaba un área de $80 \mathrm{~m}$. de longitud y $20 \mathrm{~m}$. de anchura, y un templo en el del sureste.

Junto al foro se hallaron restos de unas modestas termas y de un mercado (macellum). En cambio, el gran conjunto termal se encontraba alejado del foro, en la zona denominada "Los Arcos". Por su planta recuerda a los del norte de Africa y muchas de sus dependencias debieron de estar decoradas con ricos materiales, mármoles, mosaicos policromos, etc.

El teatro se edificó en la ladera noreste del Alto del Castro, excavándose en la roca los graderios inferior y medio (ima cavea y media cavea), construyéndose de mampostería el superior (summa cavea). Los dos primeros estaban divididos en cuatro sectores (o cunei) y la tercera en ocho. En la decoración de la fachada del escenario (frons scenae) se utilizaron capiteles corintios y el estrado (pulpitum) se construyó sobre arquerias. Se supone que su edificación tuvo lugar en la época de Tiberio.

Segisamo (Sasamón), también en la provincia de Burgos, estuvo asentada sobre un antiguo castro prerromano, donde se encontró una tésera de cobre en forma de toro, escrita en caracteres ibéricos.

Otras ciudades con importantes edificios de época romana, en la provincia de Soria son las siguientes: 
Numantia, situada en el Cerro Garray (67 m. de altura), fue reconstruida después de su rendición y conquista por Escipión en el 133 a.C. González Simancas que realizó excavaciones en ella, desde 1913 hasta 1923, habló ya de la existencia de dos ciudades celtibéricas anteriores a la fecha de su caída en manos de los romanos, en el 133 a.C., de una ciudad romana destruida en época de Claudio el Gótico, hacia el 270 d.C. y de una nueva ciudad romana, superpuesta a la anterior, correspondiente al Bajo Imperio. Sin embargo, Wattemberg, quien desde 1961 realizó algunas excavaciones de tipo estratigráfico en la parte superior de la ciudad, discrepó de tales teorías, dividiendo la periodización de la ciudad en las cinco fases que van desde el Eneolítico al siglo vI d.C. En su opinión las plantas que hoy se conocen de la ciudad son romanas y posteriores al 133 a.C, a juzgar por la planimetría urbanística y por los datos estratigráficos obtenidos. También Schulten, en su día, no sólo localizó los campamentos y cuarteles, sino también restos de algunas villas romanas, correspondientes a épocas de florecimiento de la nueva Numancia.

La ciudad, de planta oval (según Wattemberg ya de época romana) estuvo rodeada por murallas de estructura trapezoidal que alcanzaron los $3,40 \mathrm{~m}$. de altura por $2 \mathrm{~m}$. de espesor (figura 6). En su interior, sus ejes mayores median 720 y $310 \mathrm{~m}$. respectivamente. Paralelos a ambos, las calles, pavimentadas y con pasaderas para ser utilizadas los días de lluvia,

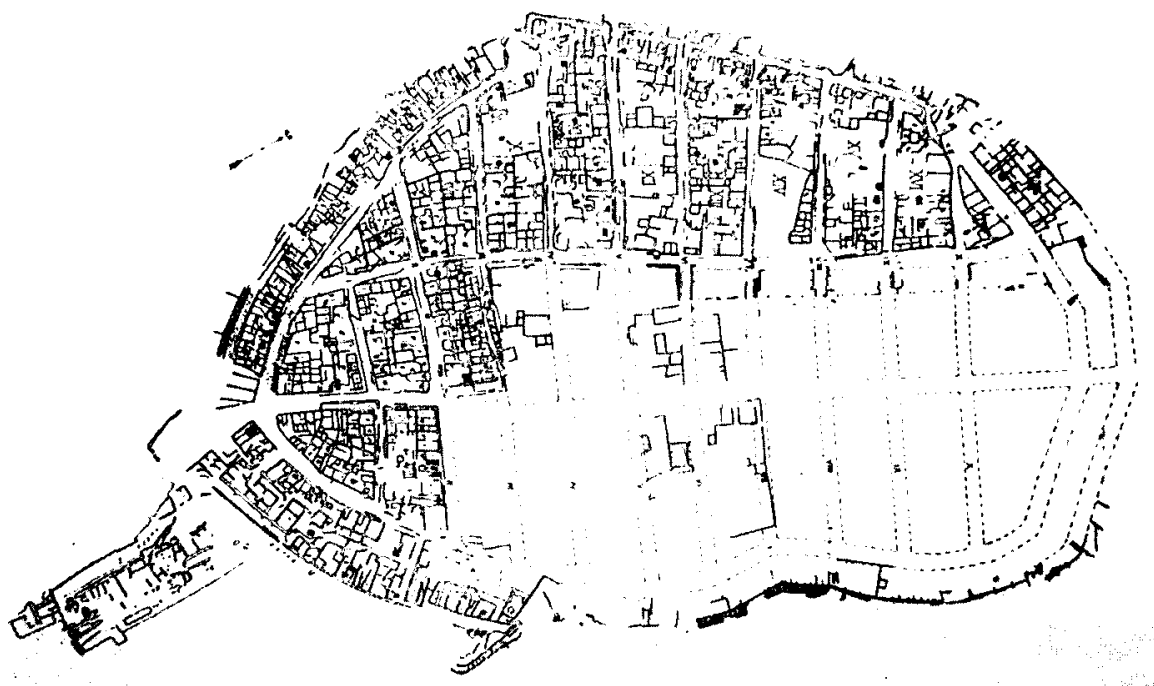

Figura 6. Plano de la ciudad de Numancia (Soria). 
estaban trazadas en forma de retícula. Las casas, yuxtapuestas entre sí, se alzaron sobre cimientos y zócalos de piedra, siendo sus paramentos y muros interiores de adobes, y los techos de ramaje y paja. Rasgo caracteristico de las viviendas numantinas fue la existencia, en la mayoria de ellas de una bodega o cueva de forma prismática. El hogar, hecho de piedras ocupaba el centro de la sala de estar, la pieza principal de la casa, aparte del vestibulo y otra dependencia secundaria.

Según Tito Livio la población fue de unos 16.000 habitantes; según los cálculos de Schulten de unos 8.000 , repartidos en unas 2.000 casas, dominando un territorio de $50 \mathrm{~km}$. de norte a sur y de $20 \mathrm{~km}$. de este a oeste. Sin embargo, su capacidad de albergue podía se mucho mayor en momentos de peligro, como sucedió en el año 153 a.C., fecha en la que reunió a 20.000 guerreros y un elevado número de refugiados. En su etapa final, por el contrario, y según las últimas cifras barajadas, se supone que fueron unos 4.000 habitantes los encerrados tras las murallas antes de su rendición (figura 7 ).

En el interior de su recinto se halló una abundante colección de vasos cerámicos, correspondientes a distintas épocas celtibéricas y romanas, fibulas, terra sigillata, armas, monedas, etc. Sobre los restos de la antigua ciudad celtibérica se aizó la romana que fue destruida hacia el 270 d.C.,

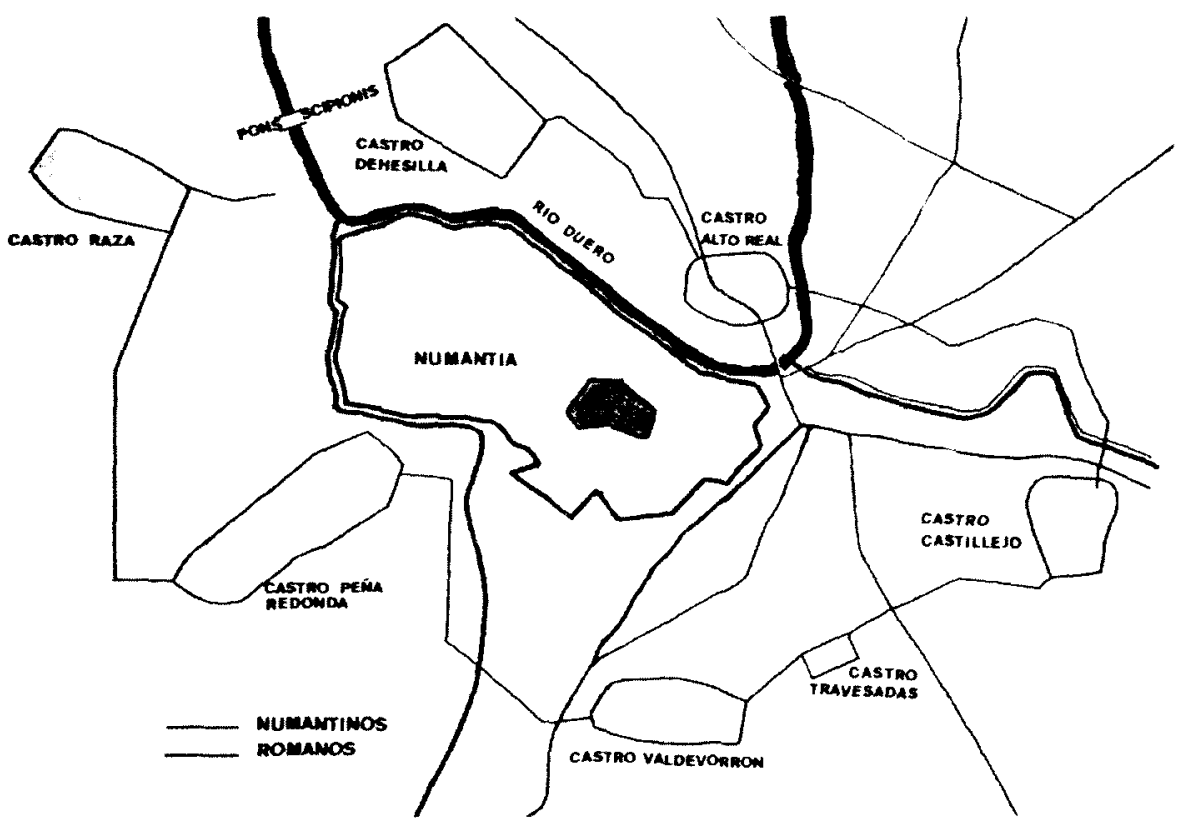

Figura 7. Esquema del cerco de los ejércitos romanos a la ciudad de Numancia (Soria) 
en época de Claudio el Gótico, y sobre ella se reedificó la correspondiente al Bajo Imperio. A pesar de las once hectáreas que ya han salido a la luz, hay que tener en cuenta que aún quedan otras tantas sepultadas y en espera de nuevas excavaciones (figura 8).

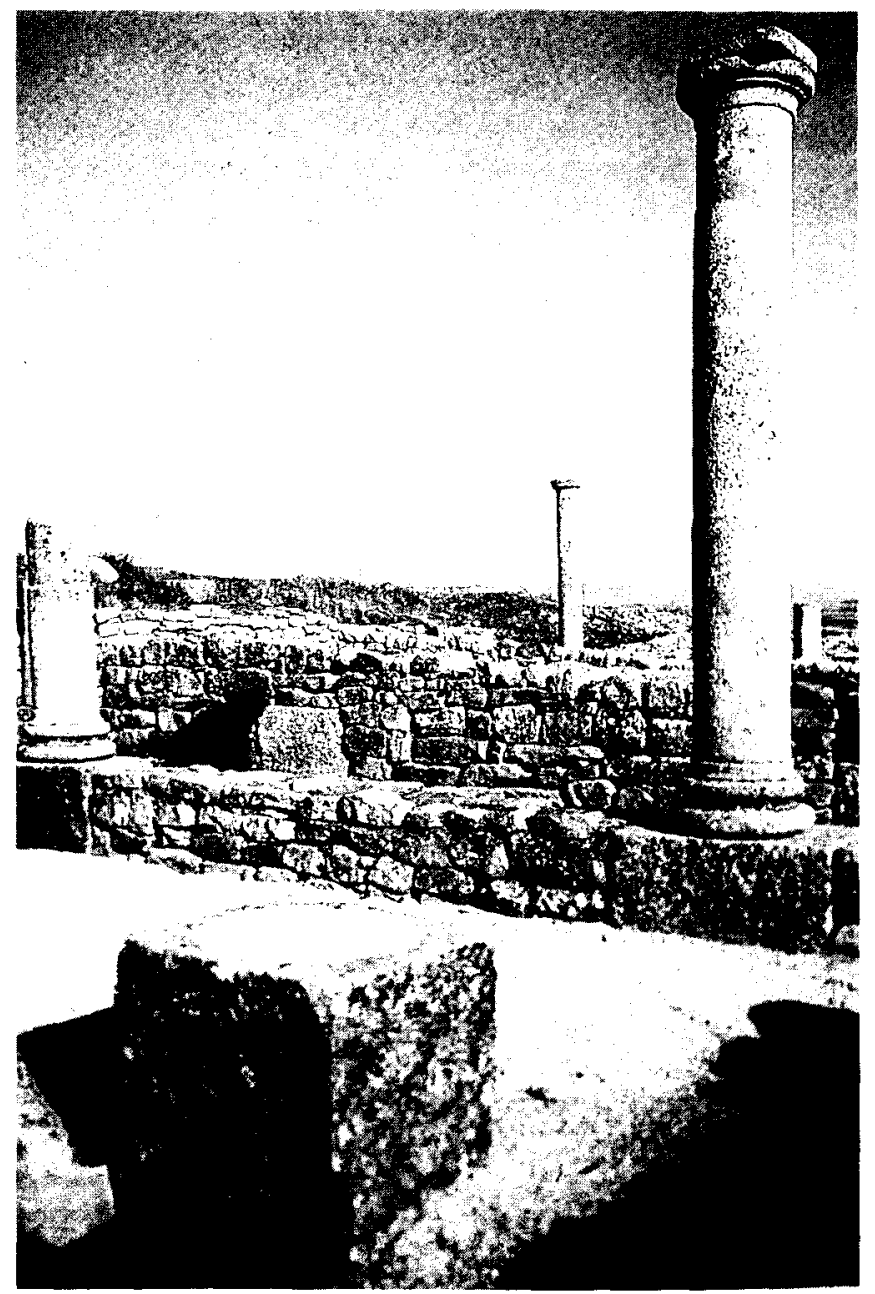

Figura 8. Casa con peristilo de Numancia (Soria).

Termancia (Tiermes), citada por Apiano, Livio, Salustio, etc., como uno de los más importantes núcleos de resistencia arevaca, no tuvo el trágico final de Numancia, pero el cónsul T. Didio la obligó a derruir sus fortificaciones aunque la permitió mantenerse en el mismo sitio. sin trasladar su 
1 Museo

2 Muralla Romana

3. Puerta del Sol

4 Graderio Rupestre

5 Edificaciones Rupestres

6 Casa de las Hornacinas

7 Casa del Acueducto

8 Casa de Vecinos

9 Canal Sur del Acueducto

10 Canal Norte del Acueducto

11 Puerta del Sol

12 Castellum Aquáe

13 Foro Imperial

14 Ermita Románicá
'Museo

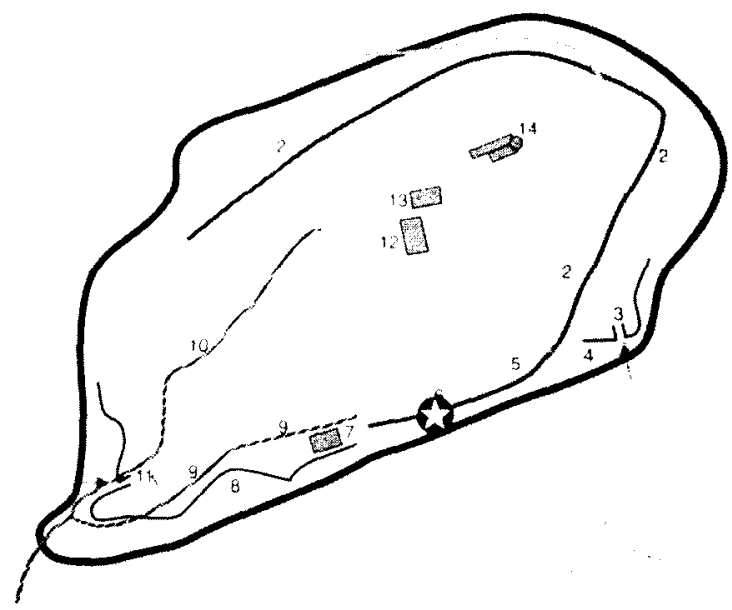

Figura 9. Plano de la antigua ciudad de Tiermes (Soria).

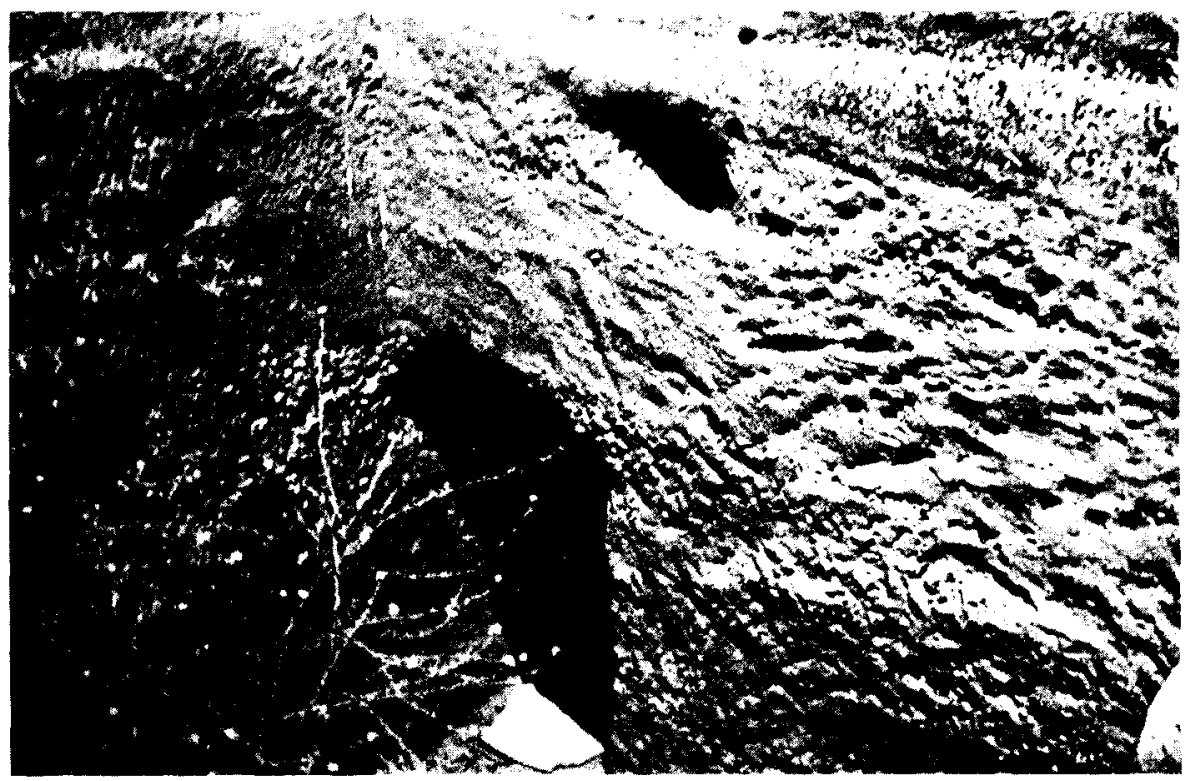

Figura 10. Casa rupestre de Tiermes (Soria). 
población al llano, aunque parte de ella debió de abandonar la ciudadela, eligiendo para su nuevo emplazamiento un valle situado al sureste, entre Manzanares y Sotillos de Caracena. Situada al norte de la Sierra de Pela, a unos $1.200 \mathrm{~m}$. sobre el nivel del mar, ocupó la parte más elevada de un cerro bien defendido por escarpadas laderas, que alcanza los $84 \mathrm{~m}$. de altura (figuras 9 y 10 ).

En época imperial la ciudad se extendió por la vertiente oriental del cerro y posiblemente fue en el siglo । d.C. cuando se construyó todo el lienzo de muralla correspondiente a este sector. De este periodo es el túnel de la parte baja de la acrópolis que conduce a la galería, considerado como un acueducto para la distribución del agua. En esta zona se encuentra la llamada casa del acueducto, una mansión romana de grandes dimensiones, fechada entre los siglos I y II d.C. y en la que se han encontrado restos de pinturas murales. Excavada en sucesivas campañas, a partir de 1979, tiene una superficie de $1.800 \mathrm{~m}^{2}$, y aparece distribuida en treinta y cinco habitaciones. La casa, de planta rectangular y espaciosas habitaciones, queda delimitada por cuatro calles trazadas en la roca arenisca. Al oeste de la ermita de Santa María (de estilo románico, edificada entre los siglos XII y XIII), el punto que se considera el núcleo original de Tiermes, se halla una gran construcción que se cree que pudo ser el castellum aquae, y que está rodeada de restos de casas romanas y grandes

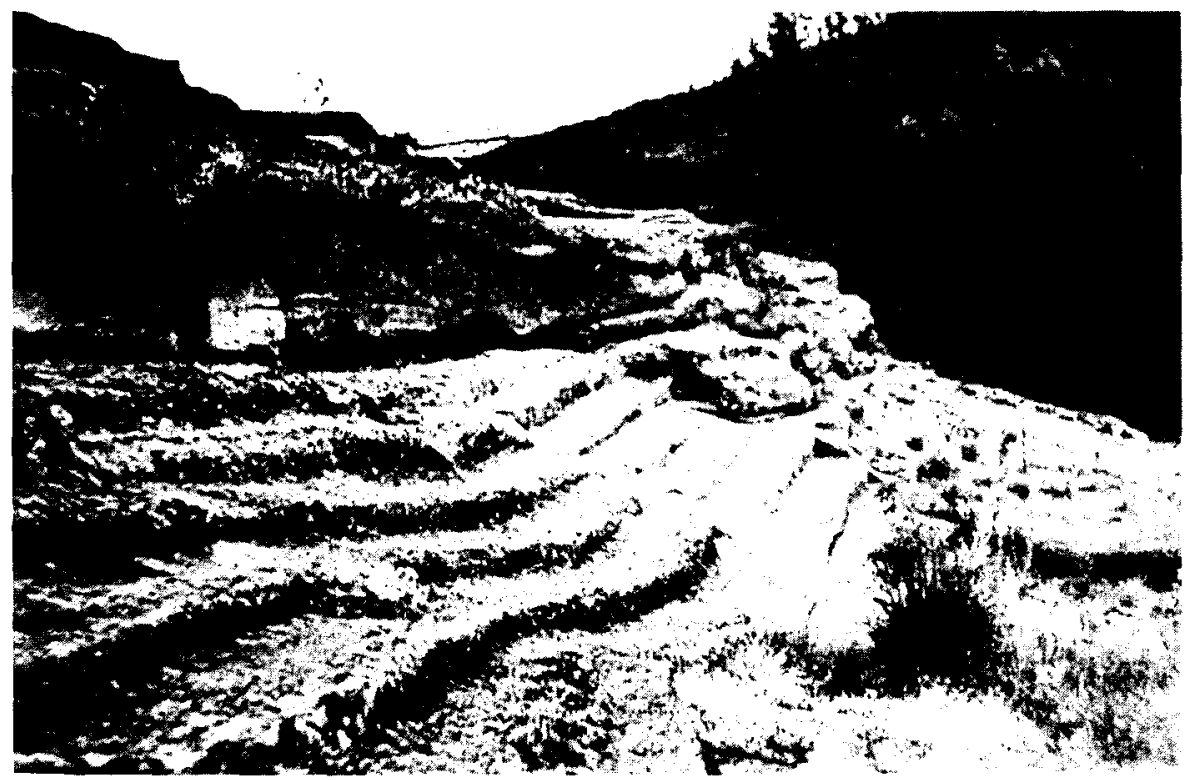

Figura 11. Graderio de un edificio público de la ciudad de Tiemes (Soria). 
edificios públicos. Entre ellos se han localizado y excavado los restos del foro, así como una serie de graderíos considerados por Taracena como un rudimentario teatro (figura 11). Al sureste de la ciudad se edificaron asimismo, unas termas.

La muralla es obra de la segunda mitad del siglo III d.C. Defiende tres lados de la ciudad (un $60 \%$ de su perímetro), ya que en su sector occidental está defendido por cortados que aseguran su inexpugnabilidad. La muralla se compone de dos paramentos, uno interno y otro externo, constitujdos ambos por sillares de arenisca (caliza y toba en menor proporción), colocados a hueso. El relleno interno, entre ambos paramentos, era de piedras calizas cogidas con argamasa, alcanzando un grosor de unos cuatro metros, por término medio. Las puertas de acceso fueron las llamadas del Sol, en el sureste y el oeste, ambas talladas en la roca arenisca del cerro, $y$ en el lado meridional una pequeña tallada en el lienzo de la muralla.

Uxama (Osma) donde se han hallado restos de un importante conjunto termal y se ha excavado la zona del foro es otra de las más renombradas ciudades de la provincia de Soria (figura 12).

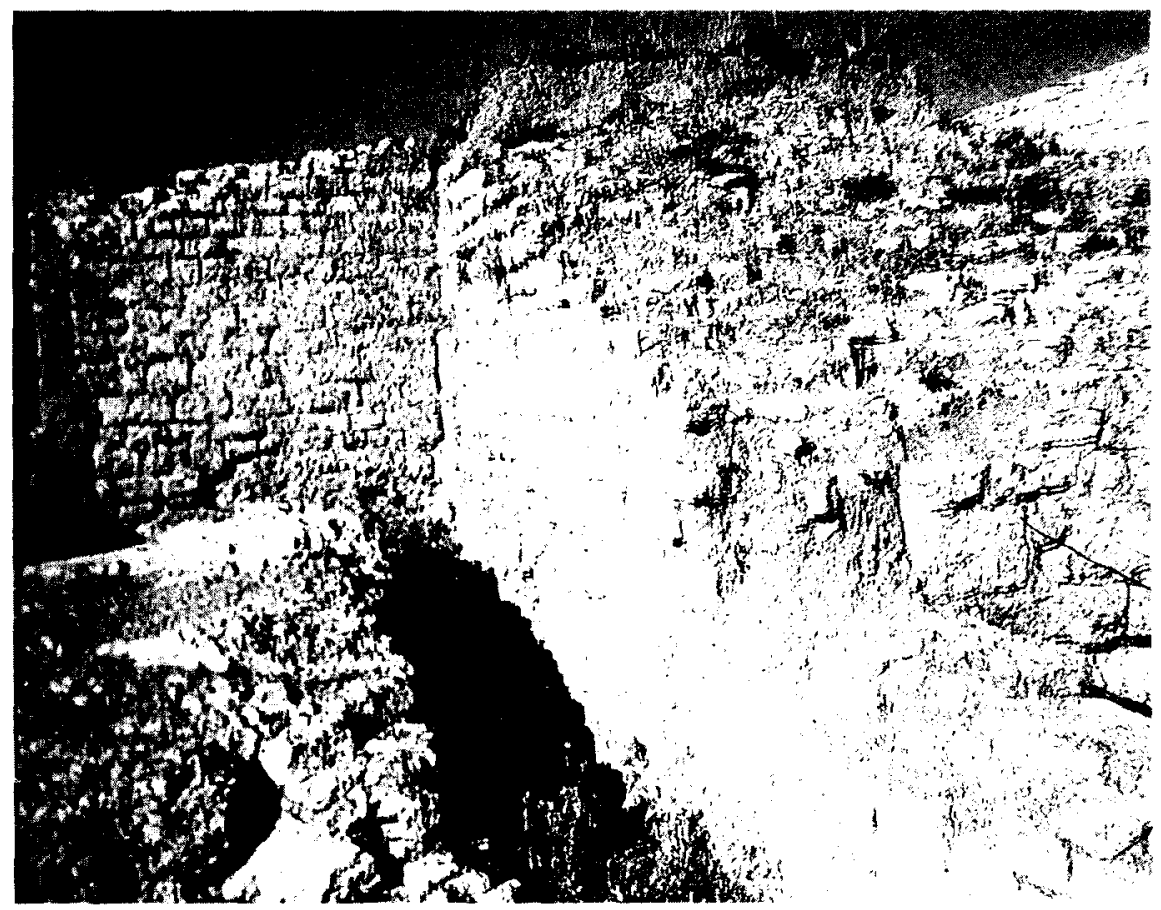

Figura 12. Ruinas de la ciudad de Uxama, actual Osma (Soria). 
Pallantia (Palencia), citada por Ptolomeo y Estrabón, como capital de los vacceos y por el importante papel que desempeñó en las guerras de la conquista de la Meseta. Se hallaba situada en la vía que iba Asturica Augusta (Astorga) a Tarraco (Tarragona). P. Mela alude a ella junto con Numancia como ciudad famosa en el interior de la Tarraconense. Los campi Palentini, como ya los cita Orosio fueron definitivos para el aprovisionamiento de trigo durante la guerra de Numancia. Al finalizar las guerras sertorianas pasó a formar parte de los pueblos sometidos del Conventus Cluniensis, apareciendo su territorio como solum tributarium. En época tardía fue saqueada por los mercenarios germanos, en el 409 y, más tarde, destruida por los godos. En época visigoda se construyó una cripta dedicada a San Antolín y que aún se conserva como tal en la actual catedral gótica.

Helmantika o Salmantika (Salamanca) que en época romana alcanzó una gran importancia, probablemente fue la misma ciudad de Salmantiké o Salmantida citada por Plutarco y Plinio el Viejo como una gran ciudad de Iberia, asediada por Anibal en el 220 a.C. Los hallazgos que recientemente se han localizado en el cerro San Vicente parece ser que vienen a confirmar lo dicho por los citados autores. De la ciudad romana no quedan más vestigios que restos de la muralla y la mitad del llamado puente mayor del Tormes. El otro medio fue reedificado en el siglo XVI, según la noticia transmitida por Juan Ramón Trasmiera en el Triunfo de Raimundino: La puente fue edificada / Por artificio romano / Lo otro medio es hispano. En realidad los quince arcos próximos a la ciudad son originales y los restantes se reconstruyeron después de la avenida de San Policarpo en 1626, como consta en una inscripción de 1677, visible en uno de los postes que hay a la entrada del puente. Ciudades importantes, en época de Augusto, fueron también, en la provincia de Salamanca, Mirobriga (Miróbriga) y Bletisa (Ledesma).

De la ciudad de Abula o Abila (Ávila) sólo se tiene una mención antigua que es la de San Jerónimo, cuando se refiere a ella como ciudad en la que Prisciliano fue obispo. Su nombre se ha relacionado con los celtibéricos de Abiculum, Abulocum, etc. Su importancia prerromana está certificada por el yacimiento de la Edad del Bronce de las Cogotas y es muy probable que en sus cercanías existiera, asimismo un poblado romano.

A este breve comentario de las principales ciudades romanas de la Meseta septentrional habría que añadir las calzadas, puentes, pantanos, acueductos, arcos, monumentos honoríficos, villas, etc., con cuyos vestigios se puede reconstruir los sistemas de vida imperantes desde el siglo । a.C. hasta la Alta Edad Media. 


\section{BIBLIOGRAFIA}

\section{La romanización}

Avello Álvarez, J.L. (1990): “El arte romano en León”, en Historia del Arte en León, León ABASOLO, J.A. (1985): «El arte romano en Burgos», en Historia de Burgos, tomo I

MañAnes, T. (1979) : Arqueologia vallisoletana, I, Valladolid. - (1983): "La implantación romana en el territorio leonés", en Lancia, !, págs. 152 y ss.

Sanz Minguez, C. y Lopez Rodriguez, J.R. (1988): "Hallazgos romanos y visigodos en Padilla de Duero (Valladolid)", Archivos leoneses, 83, 84, págs. 291-312.

\section{Urbanismo. Las ciudades}

BAL IL, A. (1977): Segovia y la Arqueologia Romana. Barcelona.

Blanco Garcia, J.F. (1986): Coca Arqueológica, Madrid.

- (1988): "Coca Arqueológica", Rev. De Arqueología, n 81, págs. 47-55.

Garcia y Bellido, A. (1966): Urbanistica en las grandes ciudades del Mundo Antiguo, Madrid.

- (1950): "La Legio VII Gemina y los origenes de la ciudad de León», en B.R.A.H, Madrid.

- (1970): “Estudios sobre la Legio VII Gemina y su campamento en León». En Legio VII, págs. 571 y ss.

Frutos Cuellas, J.L. de. (1981): Cauca en la romanización, Segovia

GaliNDO, M. (1957): "La ciudad de León», en Estudios Geográficos, n 66.

Ortego, T. (1977): "Perduración de las ideas urbanisticas del Alto Duero", en Symposium de las Ciudades Augústeas II (1976), Zaragoza, págs. 201-208.

Palol, P. (1982): Guia de Clunia, Valladolid.

(1943): Cántabros y astures y su segunda guerra con Roma, Madrid.

Zamora, A. (1987): "Segovia en la Antigüedad", en Historia de Segovia, Segovia.

FERnÁndez CASAdO, C. (1972): Acueductos romanos en España, Madrid.

- (1973): Puentes romanos en España, Madrid.

Gomez de SOMORRostro, A. (1820): El acueducto y otras antigüedades de Segovia, Madrid.

Ramirez Gallardo, A. (1984): El acueducto de Segovia, Valencia.

ROLDAN, J.M. (1975): Itineraria hispana. Fuentes antiguas para el estudio de las vias romanas en la Península lbérica. Valladolid-Granada,

Rodriguez, J. (1970): “Las vias militares romanas en la actual provincia de León», en Legio VII Gemina, págs. 405 y ss. León.

SMITH, N. (1978): "Tecnologia hidráulica romana", Investigación y Ciencia, Julio, págs. 88 y ss. - (1983): Ingenieria hidráulica romana, Madrid. 